\section{Comitês Nacionais de Bioética na União Europeia: contribuição para a discussão na América Latina}

\author{
Schlemper Junior, BR \\ Doutor em Medicina, Mestrado em BioCiências e \\ Saúde/Universidade do Oeste de Santa Catarina/Brasil; \\ schlemper.junior@gmail.com
}

Sanchez Gonzalez, MA

Doutor em Bioética/Universidade Complutense de Madri/Espanha.

PALAVRAS-CHAVE: Bioética, Comitê Nacional de Bioética, União Europeia, Ciência/ Novas Tecnologias, Educação.

Introdução: Estimulados e apoiados pela Unesco [1,2] muitos países criaram órgãos consultivos denominados de Conselho/Comitê Nacional de Bioética (CNB) [3]. Suas competências maiores são: estudar e promover reflexões éticas sobre o valor e a importância das novas tecnologias, os procedimentos em evolução na medicina e sua aplicação na saúde humana e nas ciências da vida visando recomendar possíveis soluções às autoridades, com primordial papel na educação bioética ao público em geral [4]. Alguns países da América Latina e Caribe possuem CNB em funcionamento, enquanto outros apenas aprovaram leis de criação e alguns nada projetam. No Brasil, ocorreram tentativas frustradas [5]. O presente estudo objetivou estimular e subsidiar estes países a discutirem a perspectiva de seu aprimoramento ou implantação. Métodos: A pesquisa foi realizada entre 2015 e 2016 e constou de: a) obtenção de informações sobre os CNB por pesquisa bibliográfica, dados da UNESCO, da Comissão Europeia, dos websites e por correio eletrônico; b) aplicação de questionário estruturado com 10 questões a 30 membros de comités de ética, professores universitários da saúde e do direito e do Comité Nacional de Bioética, na Espanha. Resultados: Dos 28 países da União Europeia, à época, 24 (85,7\%) possuíam CNB, criados a partir de 1983 , predominantemente por lei federal, de perfil interdisciplinar e de igualdade de gênero, com 10 a 19 membros, de atuação independente, mas vinculados administrativamente ao Ministério da Saúde e com presidente nomeado pelo ministro correspondente para mandato de quatro anos, renovável ou não. Preponderaram temas relacionados ao progresso científico, à integridade em pesquisa e à assistência à saúde. Suas reflexões são públicas e não vinculantes, com ênfase na educação do público. Em relação aos 30 entrevistados, 3 não recomendaram a criação do $\mathrm{CNB}$, porém não se oporiam $(10 \%)$ e $27(90.0 \%)$ recomendaram sua criação no Brasil, sendo que 19 deles de forma incisiva e 8 sem grande entusiasmo. Onze $(42,3 \%)$ deles sugeriram que o CNB fosse criado por entidade médica ou científica de nível nacional, a qual também nomearia seus membros, funcionando de forma independente, com 10 a 14 membros docentes, pesquisadores em bioética e representantes de setores sociais majoritários e minoritários da sociedade para abordar, sobretudo, os mesmos temas enfatizados pelos CNB da União Europeia. Ainda, destacaram sua importância para subsidiar eticamente a edição de normas legais pelo Poder Executivo, Legislativo e Judiciário, bem como para suporte ético às políticas públicas de saúde. Suas reflexões ocorreriam por iniciativa própria e por solicitação dos poderes constituídos, contribuindo para o desenvolvimento de cultura bioética no país. Conclusões: Conclui-se pelo relevante papel desempenhado pelos CNB permanentes nos países da União Europeia na orientação ética sobre temas capazes de criar um "novo poder" susceptível de ameaçar a dignidade humana, os direitos humanos e, até mesmo a humanidade. Outra relevante função é deliberar sobre questões éticas e dilemas morais que surgem no contexto dos modernos cuidados de saúde e na imprescindível atuação de comunicar e educar a sociedade. Para o Brasil, recomendou-se, majoritariamente, a criação do CNB por instituição independente, médica ou científica.

Agradecimentos: À Coordenação de Aperfeiçoamento de Pessoal de Nível Superior (CAPES) pela concessão da Bolsa de Estágio Sênior na Universidade Complutense de Madri.

\section{REFERÊNCIAS}

[1] UNESCO. United Nations Educational, Scientific and Cultural Organization. France (2005). Disposable: http://unesdoc.unesco.org/images/0013/001393/139309e.pdf

[2] UNESCO. United Nations Educational, Scientific and Cultural Organization. France (2010). Disposable: http://unesdoc.unesco.org/images/0018/001895/189548e.pdf [3] FERNANDEZ, JAD. Granada/España: Editorial Comares (2007).

[4] LEE, LM; WICAI, V H ; AULT, A.M. The Presidential Bioethics Commission: Pedagogical Materials and Bioethics Education, Hastings Center Report. 43(5):16-19 (2013).

[5] GARRAFA, V; Have, HT. J. Med. Ethics, 36(2):99-102 (2010). 